\title{
Characterization of host tolerance to Striga hermonthica
}

\author{
Jonne Rodenburg ${ }^{1,2, *}$, Lammert Bastiaans ${ }^{1}$ \& Martin J. Kropff ${ }^{1}$ \\ ${ }^{1}$ Crop and Weed Ecology Group, Wageningen University, P.O. Box 430, 6700 AK Wageningen, The Netherlands; \\ ${ }^{2}$ Africa Rice Center (WARDA), 01 BP 2031, Cotonou, Benin \\ ( ${ }^{*}$ author for correspondence: e-mail: j.rodenburg@cgiar.org)
}

Keywords: defence mechanisms, parasitic weed, selection measures, Sorghum bicolor

\begin{abstract}
Summary
One of the most promising control options against the parasitic weed Striga hermonthica is the use of crop varieties that combine resistance with high levels of tolerance. The aim of this study was to clarify the relation between Striga infestation level, Striga infection level and relative yield loss of sorghum and to use this insight for exploring the options for a proper screening procedure for tolerance. In three pot experiments, conducted in Mali (2003) and The Netherlands (2003, 2004), four sorghum genotypes were exposed to a range of Striga infestation levels, ranging from 0.0625 to 16 seeds $\mathrm{cm}^{-3}$. Observations included regular Striga emergence counts and sorghum grain yield at maturity.

There were significant genotype, infestation and genotype $\times$ infestation effects on sorghum yield. The relation between infestation level and infection level was density dependent. Furthermore, the relation between Striga infection level and relative yield loss was non-linear, though for the most resistant genotype Framida only the linear part of the relation was obtained, as even at high infestation levels only moderate infection levels were achieved. The results suggest that for resistant genotypes, tolerance can best be quantified as a reduced relative yield loss per aboveground Striga plant, whereas for less resistant genotypes the maximum relative yield loss can best be used. Whether both expressions of tolerance are interrelated could not be resolved. Complications of screening for tolerance under field conditions are discussed.
\end{abstract}

Abbreviations: ASNPC, area under the Striga number progress curve; $\mathrm{DW}_{\mathrm{kernel}}$, dry weight of kernel yield (g); $\mathrm{NS}_{\max }$, maximum aboveground Striga numbers; RYL, relative yield loss $(\%)$; $\mathrm{Y}_{\mathrm{s}}$, observed yield of an individual plant grown under Striga infestation $(\mathrm{g}) ; \mathrm{Y}_{\mathrm{c}}$, average kernel yield of all control plants of a specific genotype $(\mathrm{g})$

\section{Introduction}

The obligate hemi-parasitic weed Striga hermonthica (Del.) Benth is a major constraint to cereal production in the semi-arid to sub-humid tropics of Africa. Yields of host plants infected by Striga can be severely reduced (Obilana, 1983; Rodenburg et al., 2005). Among host species for Striga are some important crops like sorghum (Sorghum bicolor (L.) Moench), pearl millet (Pennisetum glaucum (L.) R. Br.), maize (Zea mays (L.)) and upland rice (both Oryza glaberrima (Steudel) and $O$. sativa (L.).

One of the most promising control options against Striga is the use of crop varieties with improved levels of resistance and tolerance against this parasite. Resistant genotypes have fewer infections, while tolerant genotypes show less impairment of growth or losses in grain yield when exposed to similar levels of infection than other varieties of the same species (Parker $\&$ Riches, 1993). The converse of resistance is susceptibility, while the converse of tolerance is sensitivity. Every host genotype combines a specific level of resistance with a specific level of tolerance. Breeding for those characteristics requires suitable selection criteria. Many different selection measures have been developed for resistance. All of these measures are based on the number of aboveground Striga plants and vary from a single count at a specific moment in 
time (Adetimirin et al., 2000a; Omanya et al., 2004) or the maximum number of aboveground Striga plants (Wilson et al., 2000, 2004; Rodenburg et al., 2005) to the area under the Striga number progress curve (ASNPC) (Adetimirin et al., 2000a; Haussmann et al., 2000; Wilson et al., 2000, 2004; Omanya et al., 2004; Rodenburg et al., 2005). Complete resistance, also referred to as immunity against Striga, has not yet been found. Therefore, a host variety that combines superior levels of resistance and tolerance is an obvious breeding objective and has been proposed in many studies (Kim, 1991; DeVries, 2000; Kling et al., 2000; Haussmann et al., 2001a,b; Pierce et al., 2003; Showemimo, 2003; Rodenburg et al., 2005).

Different measures of tolerance have been proposed, ranging from host plant damage scores to yield, yield loss, or relative yield loss under Striga infestation (Efron, 1993; Kim, 1994; Adetimirin et al., 2000b; Gurney et al., 2002; Kim et al., 2002). None of these measures account for the difference in resistance among genotypes and hence they ignore the fact that the observed damage is due both to Striga infection level (resistance) and the extent to which the specific genotype endures these infections (tolerance). Consequently, differences among genotypes in level of yield reduction can not simply be attributed to tolerance only. It seems that the only way to obtain an unbiased comparison of the level of tolerance among genotypes would be to create identical infection levels for all genotypes. Theoretically this might be achieved by exposing all genotypes to a range of infestation levels. However, realization of such a range under field conditions is difficult, if not impossible, and definitely costly. Another alternative might be to correct the observed damage of each genotype for its Striga infection level. Such a correction requires that the relation between Striga infection level and yield loss is known. Studies in which the biomass of the parasite was used as infection measure suggest that the relation between Striga infection level and yield loss is non linear and characterized by a diminishing slope with increasing infection level (Gurney et al., 1999, 2000). Whether this type of relation also holds for the relation between Striga number and yield loss is not yet clear. Nor is it known whether such a relation has a general validity or is genotype specific.

The aim of this study was to resolve the relationship between Striga infestation level, Striga infection level and yield loss for a number of sorghum genotypes, and to explore options for the develop- ment of a screening procedure for tolerance to Striga infection.

\section{Material and methods}

\section{Experimental sites and plant material}

Four sorghum (Sorghum bicolor L. Moench) genotypes were grown at a range of Striga (Striga hermonthica (Del.) Benth.) infestation levels, including Striga free controls, in pot experiments in Mali (2003) and the Netherlands $(2003,2004)$. The sorghum genotypes used in this study (CK60-B, E36-1, Framida and Tiémarifing) were selected for their supposed differences in resistance and tolerance. CK60-B and E36-1 represented very susceptible and sensitive genotypes (van Ast et al., 2000, D.E. Hess personal communication). Framida represented a resistant genotype (El-Hiweris, 1987) while Tiémarifing was selected for its high tolerance (van Ast et al., 2000; Gurney et al., 1995). The Striga hermonthica seeds, used for infestation were collected at Samanko, Mali in 1998 (2003W and 2004W) and 2001 (2003S) from plants parasitizing sorghum. The seed viability was $70 \%$ (2003 Wageningen), 88\% (2003 Samanko) and 60\% (2004 Wageningen). In all experiments, only the upper $10 \mathrm{~cm}$ of the soil in each pot was infested with Striga seeds and upon infestation the soil was kept moist for 10 days to allow preconditioning of the Striga seeds. Table 1 presents an overview of the materials and methods of the different experiments.

\section{Open-air pot experiment}

One pot experiment (2003S) was carried out in the open air from 11 July to mid November 2003 (2003S) at the ICRISAT field station in Samanko, $20 \mathrm{~km}$ Southwest of Bamako, the capital of Mali (latitude: $8^{\circ} 54^{\prime \prime} \mathrm{W}$ and $12^{\circ} 54^{\prime \prime} \mathrm{N}$, altitude: $329 \mathrm{~m}$ ). The climate type in this area is Sudanese, characterized by a single rainy season between May and October. The mean temperature during the cropping season (June-November) was $29.1^{\circ} \mathrm{C}$ and the mean annual rainfall at the field station was $950 \mathrm{~mm}$. In addition to natural rainfall, pots were watered by hand to create conditions without water limitation. Soil used for the experiment was a 3:1:2 quartz sand: arable soil: compost mixture. To improve the drainage capacity of the pots, a $3 \mathrm{~cm}$ layer of gravel was put on the bottom of each pot. 
Table 1. Summary of materials, methods and environmental conditions of the three experiments: $2003 \mathrm{~S}, 2003 \mathrm{~W}$ and $2004 \mathrm{~W}$

\begin{tabular}{llll}
\hline Parameter/Pot experiment & $2003 \mathrm{~S}$ & $2003 \mathrm{~W}$ & $2004 \mathrm{~W}$ \\
\hline Year & 2003 & 2003 & 2004 \\
Location & Samanko (Mali) & Wageningen & Wageningen \\
Environment & Open-air & Greenhouse & Greenhouse \\
Mean day temperature $\left({ }^{\circ} \mathrm{C}\right)$ & 29 & 28 & 28 \\
Pot volume $(\mathrm{L})$ & 17 & 12 & 17 \\
Fertilizer application $\left(\mathrm{kg} \mathrm{ha}^{-1} \mathrm{~N}: \mathrm{P}: \mathrm{K}\right)$ & $42.5: 42.5: 42.5$ & $50: 42: 75$ & $50: 42: 75$ \\
Plant spacing $(\mathrm{m})$ & $0.4-0.8$ & $0.3-0.8$ & $0.3-0.5$ \\
Striga viability $(\%)$ & 88 & 70 & 60 \\
Striga infestation levels & $0,0.125,0.25,0.5$, & $0,0.5,1.0$ and 3.0 & $0,0.0625$ (CK60-B and E36-1), 0.125, 0.25, 0.5, \\
$\quad$ viable seeds cm $\left.{ }^{-3}\right)$ & 1.0 and 2.0 & & $1.0,2.0,4.0,8.0$ and 16.0 (Framida and Tiémarifing) \\
Replicates & 8 & 7 & 8 \\
Sowing date & $11-\mathrm{Jul}$ & $26-\mathrm{May}$ & $28-\mathrm{Apr}$ \\
Harvest time (DAS) & 120 & $92-106$ & $106-112$ \\
\hline
\end{tabular}

This experiment consisted of a split-plot design in 8 replicates with sorghum genotype at the plot level, and 6 Striga infestation levels at the sub-plot level. Infestation levels were 0 (control), $0.125,0.25,0.5,1.0$ and 2.0 viable Striga seeds $\mathrm{cm}^{-3}$ of soil.

Pots used in this experiment had a volume of 171 and a diameter of $29 \mathrm{~cm}$. Pot spacing in the plot was $0.4 \mathrm{~m}$ (centre-centre) and plots were separated by an additional row of $0.4 \mathrm{~m}$ wide. An equivalent of $42.5 \mathrm{~kg} \mathrm{~N}, 42.5 \mathrm{~kg} \mathrm{P}$ and $42.5 \mathrm{~kg} \mathrm{~K}$ per hectare was applied in a single fertilizer (N-P-K: $1-1-1)$ dressing just prior to sowing. The sorghum seeds were sown at a rate of 5 sorghum seeds per pot. Thinning to one plant per pot was done at 17 days after sowing (DAS). Sorghum plants were harvested at 120 DAS.

\section{Greenhouse pot experiments}

Two pot experiments were conducted in a tropical greenhouse of Wageningen University in The Netherlands from 26 May to mid September 2003 (2003W) and from the 28 April to mid August 2004 (2004W). These two experiments had comparable environmental conditions. Day length was held constant at $12 \mathrm{~h}$ (between 08.00 and $20.00 \mathrm{~h}$ ). Supplemental light was provided by $400 \mathrm{~W}$ sodium vapour lamps that automatically switched on during daytime when global solar radiation dropped below $400 \mathrm{~W} \mathrm{~m}^{-2}$. Day temperatures did not fall below $28^{\circ} \mathrm{C}$. Mean relative humidity was kept between 50 and $70 \%$ for the duration of the experiments. Pots received water every two days, to create non-water-limited conditions. Soil used for both experiments was a 3:1 quartz sand: arable soil mixture.
The pot experiment of 2003 (2003W) consisted of a split-plot design in seven replicates with sorghum genotype at the plot level and four Striga infestation levels at the sub-plot level. Striga infestation levels were: 0 (control), 0.5, 1.0 and 3.0 viable Striga seeds $\mathrm{cm}^{-3}$ of soil. Pots used for this experiment had a volume of 121 and a diameter of $28 \mathrm{~cm}$. Pot spacing in each plot was $0.3 \mathrm{~m}$ and plots were separated by an additional row of $0.5 \mathrm{~m}$ wide. An equivalent of $50 \mathrm{~kg} \mathrm{~N}, 42 \mathrm{~kg} \mathrm{P}$ and $75 \mathrm{~kg} \mathrm{~K}$ per hectare was applied in a single fertilizer (N-P-K: 12-10-18) dressing at 35 DAS. The sorghum seeds were pre-germinated for $36 \mathrm{~h}$ before they were sown at a rate of three seeds per pot. Thinning to one plant per pot was done 7 DAS. Plants were harvested at physiological maturity of the different sorghum genotypes at 92 DAS (Framida), 99 DAS (E36-1 and Tiémarifing) and 106 DAS (CK60-B).

The pot experiment conducted in 2004 (2004W), consisted of a split-plot design in 8 replicates with sorghum genotype at the plot level, and 9 Striga infestation levels at the sub-plot level. A wider range of Striga infestation densities was chosen to facilitate the analysis at extreme low and high densities of Striga infection. Framida and Tiémarifing received Striga infestation densities of $0.0,0.125,0.25,0.5,1.0,2.0,4.0,8.0$ and 16.0 seeds $\mathrm{cm}^{-3}(0-10 \mathrm{~cm})$. For the more susceptible genotypes, CK60-B and E36-1, the highest infestation level was replaced by an additional low infestation level of 0.0625 seeds $\mathrm{cm}^{-3}$. Pots used in this experiment had a volume of 171 and a diameter of $30 \mathrm{~cm}$. Pot spacing in each plot was $0.3 \mathrm{~m}$ and plots were separated by an additional row of $0.2 \mathrm{~m}$ wide. An equivalent of $50 \mathrm{~kg} \mathrm{~N}, 42 \mathrm{~kg} \mathrm{P}$ and $75 \mathrm{~kg} \mathrm{~K}$ per hectare of fertilizer 
(N-P-K: 12-10-18) was applied in a single dose before sowing. The sorghum seeds were pre-germinated for $36 \mathrm{~h}$ before they were sown at a rate of three seeds per pot. Thinning to one plant per pot was done 7 DAS. Harvests of all genotypes were conducted at 105 and 106 DAS, except for plants that were not yet mature. This last category of plants was harvested at 112 DAS.

\section{Observations}

Striga counts were performed every 2-3 days, up to 61 (2003S), 56 (2003W) and 49 (2004W) DAS and were conducted weekly after these dates. From these regular Striga counts the maximum aboveground Striga numbers $\left(\mathrm{NS}_{\max }\right)$ were derived. At maturity of the cereal plants, sorghum panicles and aboveground Striga plants of every pot were harvested. Sorghum panicles were sun-(2003S) or oven- (2003W and 2004W) dried. Panicles were threshed and kernel yield $\left(\mathrm{DW}_{\text {kernel }}\right)$ was determined. The relative yield loss (RYL) was calculated as:

$$
\mathrm{RYL}=\left[\left(\mathrm{Y}_{\mathrm{c}}-\mathrm{Y}_{\mathrm{s}}\right) / \mathrm{Y}_{\mathrm{c}}\right] \times 100(\%)
$$

where $\mathrm{Y}_{\mathrm{c}}$ is the average kernel yield of all control plants of a specific genotype and $\mathrm{Y}_{s}$ is the observed yield (DW kernel of an individual plant grown under Striga infestation. Average control yields were used to reduce variability of RYL.

\section{Statistical analyses}

Data on $\mathrm{NS}_{\max }$ and $\mathrm{DW}_{\text {kernel }}$ and RYL were subjected to analyses of variance (ANOVA), followed by a comparison of means with the least significant difference (1.s.d.), using the Genstat (release 7.1) statistical software package. $\mathrm{NS}_{\max }$ and $\mathrm{DW}_{\text {kernel }}$ were subjected to square root $\left((X+c)^{1 / 2}\right.$ transformations, where $X$ is the original, individual observation and $c=0.5$ ), prior to analysis, to meet the assumptions of the analysis of variance, following procedures recommended by Sokal and Rohlf (1995). The RYL percentages were arc-sinus (or angular) transformed prior to analysis of variances, following procedures recommended by Sokal and Rohlf (1995). Negative RYL values (6 cases for $2003 \mathrm{~W}$ with $N=84,11$ cases for $2003 \mathrm{~S}$ with $N=160$ and 6 cases for $2004 \mathrm{~W}$ with $N=256$ ) were replaced by zeros before statistical analysis.

\section{Results}

Sorghum yields and infestation levels

Table 2 shows the results of an analysis of variance on $\mathrm{DW}_{\text {kernel }}$ for each experiment. In 2004, only 8 infestation levels were used in the analysis of variance. To balance the experimental design, infestation levels of 0.0625 seeds $\mathrm{cm}^{-3}$ (CK60-B and E36-1) and of 16.0 seeds $\mathrm{cm}^{-3}$ (Framida and Tiémarifing) were left out of the analysis. All experiments showed a highly significant $(P<0.01)$ genotype, infestation level and genotype $\times$ infestation level effect on $\mathrm{DW}_{\text {kernel }}$.

Yields of E36-1, Framida and Tiémarifing in the control treatment in Mali (2003S) were much higher than yields in the control treatments obtained in the greenhouse-experiments in The Netherlands (Table 3). In Mali (2003), control yield of CK60-B was significantly lower than that of the other genotypes, whereas in Wageningen $(2003 \mathrm{~W}$ and $2004 \mathrm{~W})$ control yield of CK60-B was equal or even higher (in case of E361 (2003W and 2004W) and Tiémarifing (2004W)) than that of other genotypes. Yields of CK60-B and E36-1 plants infected with Striga were always significantly lower at comparable levels of infestation, than the yields of Framida and Tiémarifing, except for Tiémarifing at the highest infestation level in 2003S. Complete crop failure was only found with CK60-B in Wageningen at infestation levels of $1.0(2003 \mathrm{~W})$ and $2.0(2004 \mathrm{~W})$ seeds $\mathrm{cm}^{-3}$ and higher.

Table 2. Analysis of variance of sorghum kernel dry weight per host plant of the three experiments: 2003S, 2003W and 2004W, with genotype and infestation level as experimental factors

\begin{tabular}{|c|c|c|c|c|}
\hline Experiment & Source of variation & df & Mean square ${ }^{a}$ & $F$-value ${ }^{\mathrm{b}}$ \\
\hline \multirow[t]{3}{*}{$2003 W$} & Genotype $(G)$ & 3 & 44.03 & 156.0 \\
\hline & Infestation level (I) & 3 & 29.22 & 136.7 \\
\hline & $G \times I$ & 9 & 6.19 & 29.0 \\
\hline \multirow[t]{3}{*}{$2003 \mathrm{~S}$} & Genotype $(G)$ & 3 & 337.98 & 38.9 \\
\hline & Infestation level (I) & 5 & 152.53 & 24.1 \\
\hline & $G \times I$ & 15 & 19.41 & 3.1 \\
\hline \multirow[t]{3}{*}{ 2004W } & Genotype $(G)$ & 3 & 98.24 & 71.7 \\
\hline & Infestation level (I) & $7^{\mathrm{c}}$ & 39.05 & 51.2 \\
\hline & $G \times I$ & 21 & 3.95 & 5.18 \\
\hline
\end{tabular}

a Data are square-root-transformed $\left((X+0.5)^{1 / 2}\right)$ to meet requirements for ANOVA.

${ }^{\mathrm{b}}$ All effects are significant at the 0.01 probability level.

${ }^{\mathrm{c}}$ To balance the design infestation levels 0.0625 (for CK60-B and E36-1) and 16 (for Framida and Tiémarifing) were excluded from the analysis. 
Table 3. Total kernel dry weight (g) per sorghum plant per genotype: CK60-B, E36-1, Framida and Tiémarifing and Striga infestation level: 0, $0.125,0,25,0.51 .0,2.0,3.0,4.0$ and 8.0 seeds $\mathrm{cm}^{-3}$ of the three experiments: $2003 \mathrm{~S}, 2003 \mathrm{~W}$ and $2004 \mathrm{~W}$

\begin{tabular}{|c|c|c|c|c|c|c|c|c|c|c|}
\hline & & & & & triga infest & on level (s & $\mathrm{ds} \mathrm{cm}^{-3}$ ) & & & \\
\hline & & 0 & 0.125 & 0.25 & 0.5 & 1.0 & 2.0 & 3.0 & 4.0 & 8.0 \\
\hline $2003 W$ & CK60-B & $25.7 a^{*}$ & & & $0.3 \mathrm{~g}$ & $0.0 \mathrm{~g}$ & & $0.0 \mathrm{~g}$ & & \\
\hline & E36-1 & $20.3 b$ & & & $6.6 \mathrm{e}$ & $3.4 \mathrm{f}$ & & $1.9 \mathrm{f}$ & & \\
\hline & Framida & $24.5 \mathrm{ab}$ & & & $21.1 \mathrm{ab}$ & $20.7 \mathrm{ab}$ & & $15.6 \mathrm{~cd}$ & & \\
\hline & Tiémarifing & $20.8 \mathrm{ab}$ & & & $14.8 \mathrm{~cd}$ & $13.0 \mathrm{~d}$ & & $18.1 \mathrm{c}$ & & \\
\hline & S.E.D. & 1.298 & & & & & & & & \\
\hline $2003 S$ & CK60-B & $47.9 \mathrm{~cd}$ & $11.8 \mathrm{fgh}$ & $15.1 \mathrm{efg}$ & $3.9 \mathrm{gh}$ & $3.9 \mathrm{gh}$ & $1.6 \mathrm{gh}$ & & & \\
\hline & E36-1 & $110.8 \mathrm{a}$ & $5.2 \mathrm{gh}$ & $0.6 \mathrm{~h}$ & $3.5 \mathrm{gh}$ & $1.0 \mathrm{~h}$ & $4.7 \mathrm{gh}$ & & & \\
\hline & Framida & $122.9 \mathrm{a}$ & $45.5 \mathrm{~cd}$ & $102.5 \mathrm{ab}$ & $80.1 \mathrm{abc}$ & $36.8 \mathrm{de}$ & $57.7 \mathrm{bcd}$ & & & \\
\hline & Tiémarifing & $99.5 \mathrm{ab}$ & $79.8 \mathrm{abc}$ & $59.3 \mathrm{bcd}$ & $47.1 \mathrm{~cd}$ & $28.1 \mathrm{def}$ & $13.3 \mathrm{efg}$ & & & \\
\hline & S.E.D. & 0.257 & & & & & & & & \\
\hline $2004 W$ & CK60-B & $40.6 \mathrm{a}$ & $2.6 \mathrm{fg}$ & $1.2 \mathrm{fgh}$ & $2.7 \mathrm{fg}$ & $0.5 \mathrm{gh}$ & $0.0 \mathrm{~h}$ & & $0.0 \mathrm{~h}$ & $0.0 \mathrm{~h}$ \\
\hline & E36-1 & $23.3 \mathrm{bc}$ & $2.8 \mathrm{fg}$ & $2.5 \mathrm{fg}$ & $2.5 \mathrm{fg}$ & $3.3 \mathrm{f}$ & $0.6 \mathrm{fgh}$ & & $1.2 \mathrm{fgh}$ & $0.5 \mathrm{gh}$ \\
\hline & Framida & $30.1 \mathrm{ab}$ & $22.9 \mathrm{bc}$ & $23.9 \mathrm{bc}$ & $20.8 \mathrm{c}$ & $19.8 \mathrm{~cd}$ & $13.0 \mathrm{de}$ & & $9.8 \mathrm{e}$ & $11.0 \mathrm{e}$ \\
\hline & $\begin{array}{l}\text { Tiémarifing } \\
\text { S.E.D. }\end{array}$ & $\begin{array}{r}26.0 \mathrm{bc} \\
0.458\end{array}$ & $10.3 \mathrm{e}$ & $12.1 \mathrm{e}$ & $8.6 \mathrm{e}$ & $10.0 \mathrm{e}$ & $11.4 \mathrm{e}$ & & $11.2 \mathrm{e}$ & $8.5 \mathrm{e}$ \\
\hline
\end{tabular}

* Means in the same column or row, followed by a different letter are significantly different at the 0.001 level of probability. Data were square root-transformed $\left((X+0.5)^{1 / 2}\right)$ for ANOVA. Means in the table are back-transformed, S.E.D. values are not.

In all experiments, yields of CK60-B and E36-1 at the lowest infestation level were already significantly lower than in the control. Tiémarifing also showed a significant yield decrease at the lowest infestation level in the two greenhouse experiments $(2003 \mathrm{~W}$ and 2004W). In 2003S, a significant yield reduction for Tiémarifing was observed beginning with the third infestation level $\left(0.5\right.$ seeds $\left.\mathrm{cm}^{-3}\right)$. Significant yield reductions in Framida were only obtained at the higher infestation levels $\left(3\right.$ seeds cm $\mathrm{cm}^{-3}$ in $2003 \mathrm{~W} ; \geq 1$ seed cm $\mathrm{cm}^{-3}$

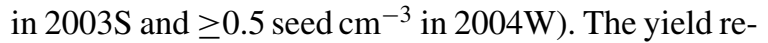
duction of Framida obtained at an infestation level of

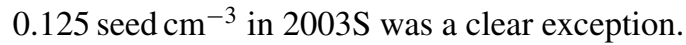

\section{Relative yield loss as a function of infestation level}

Figure 1 shows rather consistent genotype specific yield loss responses in relation to varying Striga infestation levels. Initial yield loss responses of CK60$\mathrm{B}$ and E36-1 were much more severe than those of Framida and Tiémarifing. The maximum relative yield losses of CK60-B and E36-1 approached 100\% and were generally much higher than those of Framida and Tiémarifing (always below $80 \%$ ). In the $2004 \mathrm{~W}$ experiment (Figure 1c), relative yield losses at the high infestation level of 16.0 seeds $\mathrm{cm}^{-3}$ were still only $75 \%$
(Framida) and 66\% (Tiémarifing). While relative yield losses of Tiémarifing seemed to have reached a maximum at the applied Striga infestation levels, those of Framida seemed to continue to increase. Furthermore, at the given inoculum levels, the relation between Striga infestation level and relative yield loss seemed linear for Framida whereas a clear density dependency was observed for the other genotypes.

\section{Relation between infestation and infection level}

Figure 2 shows the maximum aboveground Striga plant numbers $\left(\mathrm{NS}_{\max }\right)$ per infestation level and sorghum genotype in each experiment. The maximum number of aboveground Striga plants per host plant was much higher for all genotypes in the experiment conducted in Mali. At an infestation level of $1 \mathrm{seed} \mathrm{cm}^{-3}$, the average $\mathrm{NS}_{\max }$ values were 68.6 for $2003 \mathrm{~S}, 32.3$ for $2003 \mathrm{~W}$ and 21.2 for $2004 \mathrm{~W}$. The minimum and maximum Striga infestation levels within an experiment differed a factor $6(2003 W)$ and a factor 16 (2003S) in 2003. Despite this wide range, the differences in maximum number of aboveground Striga plants within a genotype were relatively small.

In general, CK60-B and E36-1 always had large maximum aboveground Striga numbers, whereas 

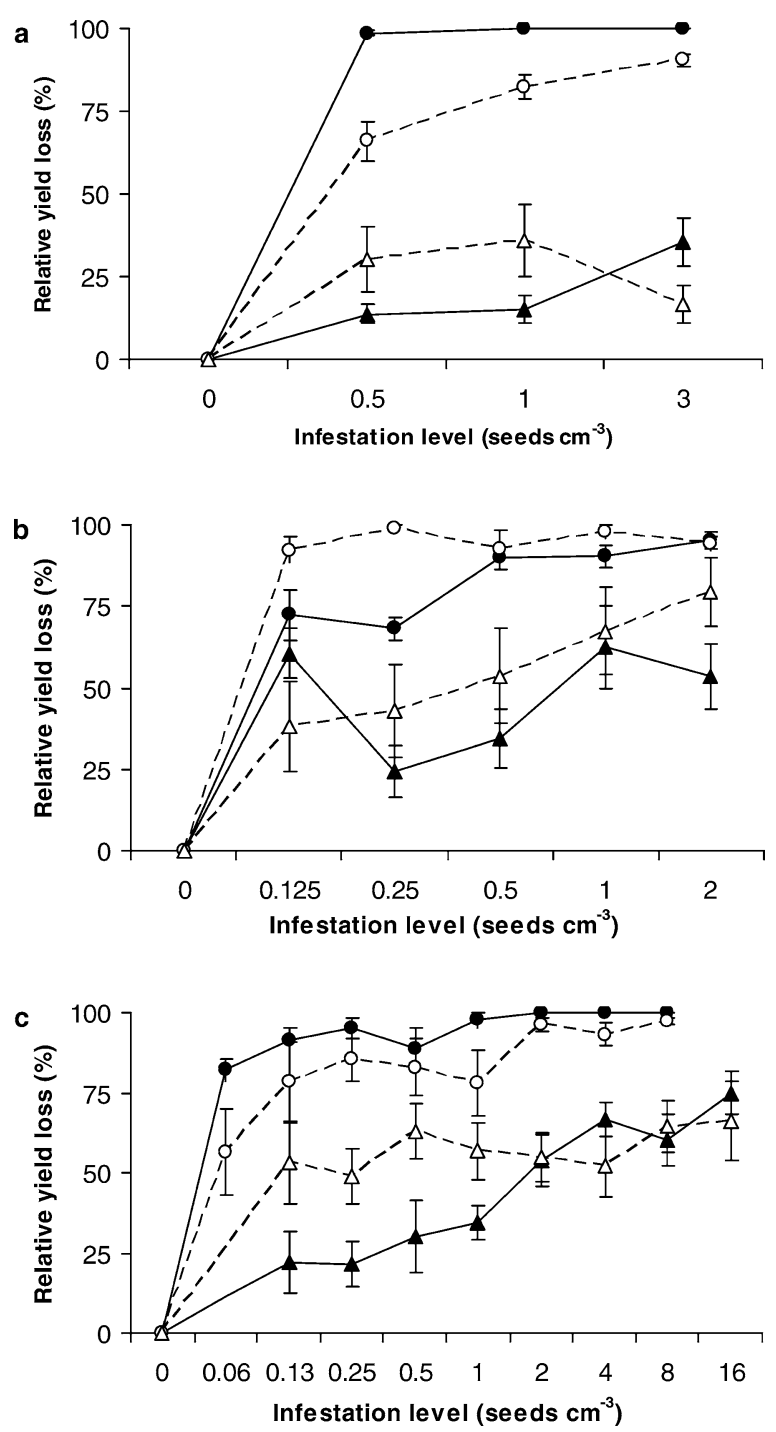

Figure 1. Relative yield loss (\%) of sorghum as a function of Striga infestation level (seeds $\mathrm{cm}^{-3}$ ) per genotype (CK60-B (•), E36-1 $(\mathrm{O})$, Framida $(\boldsymbol{\Delta})$ and Tiémarifing $(\triangle))$, observed in 2003 in the greenhouse: 2003W (a) and in the open-air: 2003S (b) and in 2004 in the greenhouse: $2004 \mathrm{~W}$ (c).

Striga numbers on Framida were always relatively small. Tiémarifing had intermediate and rather erratic infection numbers, sometimes comparable to Framida and sometimes comparable to E36-1. In 2003W, maximum aboveground Striga numbers on CK60-B and E36-1 were always significantly higher than on Framida and Tiémarifing with the exception of infestation level 1.0 where $\mathrm{NS}_{\max }$ on E36-1 was not significantly different from that on Tiémarifing. No significant genotype $\times$ infestation level effect on $\mathrm{NS}_{\max }$
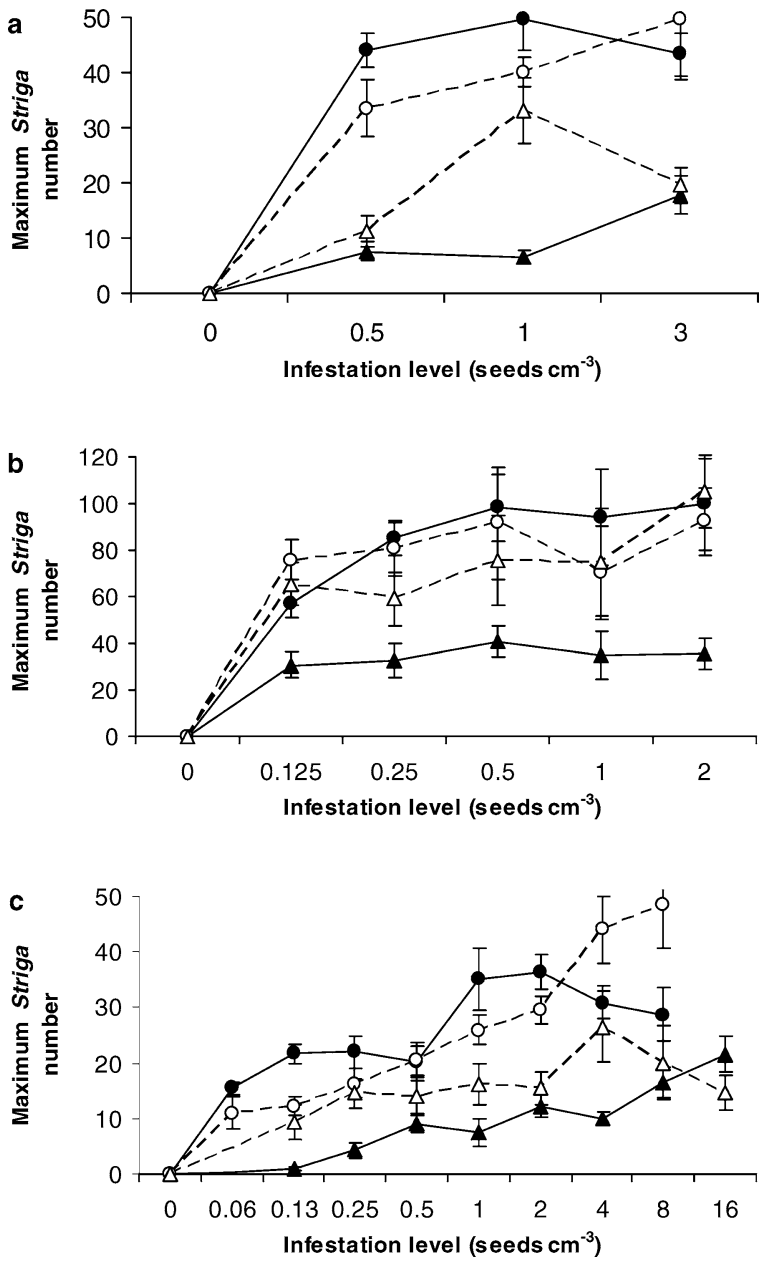

Figure 2. Maximum aboveground Striga numbers as a function of Striga infestation level (seeds $\mathrm{cm}^{-3}$ ) per sorghum genotype (CK60B (•), E36-1 (O), Framida $(\boldsymbol{\Delta})$ and Tiémarifing $(\triangle))$ observed in 2003 in the greenhouse: 2003W (a) and in the open-air: 2003S (b) and in 2004 in the greenhouse: $2004 \mathrm{~W}$ (c).

was observed in the 2003S experiment. Here Framida had a significantly lower $\mathrm{NS}_{\max }$ than the other three genotypes.

Based on these results, an even wider range of infestation levels was used in the $2004 \mathrm{~W}$ experiment. For each genotype, the highest infestation level was $128 \times$ higher than the lowest infestation level. This resulted in significant differences between the lowest and the highest maximum number of aboveground Striga plants for all genotypes. However, the high infestation range still only resulted in a ratio of 2.4 (CK60-B), 4.4 (E36-1), 23.9 (Framida) and 4.4 (Tiémarifing) between the highest and the lowest infection level. Again, $\mathrm{NS}_{\max }$ 
on CK60-B and E36-1 were always significantly higher than on Framida, while $\mathrm{NS}_{\max }$ on Tiémarifing was intermediate. For CK60-B and Tiémarifing, it appeared that within this range of infestation levels, a maximum for $\mathrm{NS}_{\max }$ was reached, whereas for E36-1 and Framida $\mathrm{NS}_{\max }$ still gradually increased with an increase in infestation level.

\section{Relative yield loss per genotype and aboveground infection level}

The average infection levels of CK60-B and E36-1 were not significantly different from one another in any experiment (Table 4). CK60-B and E36-1 had higher infection levels than Framida and Tiémarifing (except for 2003S). In the greenhouse experiments $(2003 \mathrm{~W}$ and 2004W), average relative yield loss of E36-1 was significantly lower than that of CK60-B whereas in the open air in Mali (2003S) exactly the opposite was observed. Although the infection level of Tiémarifing was always significantly higher than that of Framida, only in the $2004 \mathrm{~W}$ experiment this resulted in a significant higher average relative yield loss (RYL). Relative yield reductions of both genotypes (Framida and

Table 4. Main genotype effects on maximum aboveground Striga numbers $\left(\mathrm{NS}_{\max }\right)$ and relative yield loss (RYL: \%) of the three experiments: 2003S, 2003W and 2004W

\begin{tabular}{llrr}
\hline & & $N_{\max }$ & RYL \\
\hline $2003 \mathrm{~W}$ & CK60-B & $45.1 \mathrm{a}^{\mathrm{a}}$ & $99.4 \mathrm{a}$ \\
& E36-1 & $39.3 \mathrm{a}$ & $80.3 \mathrm{~b}$ \\
& Framida & $9.0 \mathrm{c}$ & $19.1 \mathrm{c}$ \\
& Tiémarifing & $19.3 \mathrm{~b}$ & $22.8 \mathrm{c}$ \\
& S.E.D. & 0.28 & 4.16 \\
& CK60-B & $81.4 \mathrm{a}$ & $85.0 \mathrm{~b}$ \\
& E36-1 & $77.1 \mathrm{a}$ & $97.8 \mathrm{a}$ \\
& Framida & $32.2 \mathrm{~b}$ & $45.4 \mathrm{c}$ \\
& Tiémarifing & $69.7 \mathrm{a}$ & $56.5 \mathrm{c}$ \\
& S.E.D. & 0.56 & 4.99 \\
& CK60-B & $26.6 \mathrm{a}$ & $98.1 \mathrm{a}$ \\
& E36-1 & $25.9 \mathrm{a}$ & $93.1 \mathrm{~b}$ \\
& Framida & $7.1 \mathrm{c}$ & $38.8 \mathrm{~d}$ \\
& Tiémarifing & $14.1 \mathrm{~b}$ & $58.7 \mathrm{c}$ \\
& S.E.D & 0.24 & 3.82 \\
\hline
\end{tabular}

${ }^{\mathrm{a}}$ Means in the same column, followed by a different letter are significantly different at the 0.01 (RYL) or $0.001\left(\mathrm{NS}_{\max }\right)$ probability level. Data on $\mathrm{NS}_{\max }$ were square root-transformed $(X+0.5)^{1 / 2}$ while data on RYL were arc-sinus transformed for ANOVA.

${ }^{\mathrm{b}}$ Test statistics (probabilities and S.E.D.) are based on transformed data, whereas values in table are back-transformed.
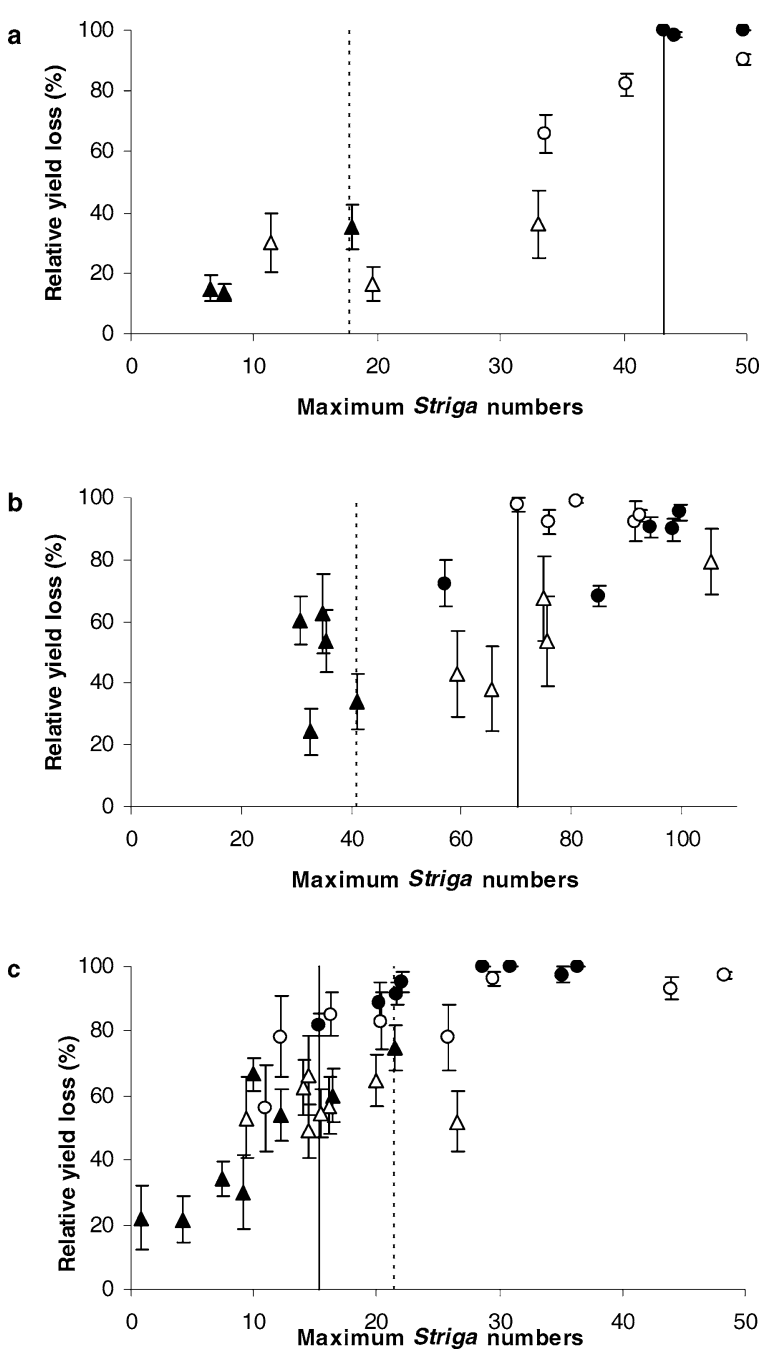

Figure 3. Relative yield loss (\%) as a function of Striga infection level (maximum Striga numbers) per sorghum genotype (CK60-B $(\bullet)$, E36-1 (O), Framida $(\boldsymbol{\Delta})$ and Tiémarifing $(\triangle)$ ), observed in 2003 in the greenhouse: $2003 \mathrm{~W}$ (a) and in the open-air: 2003S (b) and in 2004 in the greenhouse: $2004 \mathrm{~W}$ (c). Vertical lines represent the highest infection level of the most resistant genotype (dotted) and the lowest infection level of the most susceptible genotype (solid).

Tiémarifing) were significantly lower than those of CK60-B and E36-1 in all experiments.

The relationship between infection level and relative yield loss is presented in Figure 3. It is obvious that both in $2003 \mathrm{~W}$ and $2003 \mathrm{~S}$ the range of infection levels for each of the genotypes was narrow $\left(\mathrm{NS}_{\max }\right.$ in 2003W: 43-50 (CK60-B), 34-50 (E36-1), 7-18 (Framida) and 11-33 (Tiémarifing); in 2003S: 57-100 (CK60-B), 70-93 (E36-1), 31-41 (Framida) and 59-105 (Tiémarifing)). This makes it difficult to 
resolve the relation between infection level and relative yield loss of the genotypes. Furthermore, there was no specific range of infection levels in which all four genotypes were represented. A broader range of infection levels was obtained for all four genotypes in 2004. CK60-B was characterized by infection levels ranging from 15-36 Striga plants. Even at the lowest infection level, RYL was already higher than $80 \%$. At higher infection levels, 100\% RYL was observed. E36-1 had an even broader range of infection levels, ranging from 11-48 aboveground Striga plants. RYL was $55 \%$ at the lowest infection level and gradually increased until it reached nearly $100 \%$ at the highest infection level. The RYL of Framida was characterized by a nearly linear increase with Striga infection level. RYL at the lowest infection level $\left(\mathrm{NS}_{\max }=0.9\right)$ was $22 \%$ and increased to $75 \%$ at the highest infection level $\left(\mathrm{NS}_{\max }=21.5\right)$. Infection levels for Tiémarifing varied from 9 to 27 Striga plants per pot, however, RYL did not show much variation and averaged $57 \%$.

Overlapping infection levels were observed in all four sorghum genotypes in $2004 \mathrm{~W}$ (Figure 3c). This range varied from 15.4 (lowest infection of CK60-B obtained at an infestation level of 0.0625 seeds $\mathrm{cm}^{-3}$ ) to 21.5 (highest infection level of Framida obtained at an infestation level of 16 seeds $\mathrm{cm}^{-3}$ ) aboveground Striga numbers. In this range of infection levels, Tiémarifing and Framida showed to be significantly $(P<0.001)$ more tolerant than CK60-B and E36-1, with relative yield reductions of $85.3 \%$ for CK60-B, $84.1 \%$ for E361, $67.5 \%$ for Framida and $60.2 \%$ for Tiémarifing.

\section{Discussion}

The results of the 2003 experiments showed that differences in infestation level did not result in proportional differences in infection level. This clearly indicate that the relation between Striga infestation and Striga infection is density dependent, confirming earlier observations by Smith and Webb (1996). The 2003 experiments confirmed the results of earlier studies (e.g. El Hiweris, 1987; Hess 1989; Arnaud et al., 1999; van Ast et al., 2000) on the resistance of Framida and the susceptibility of CK60-B and E36-1.

Since substantial numbers of aboveground Striga plants $(>25)$ were obtained at the lowest infestation levels for most genotypes, it was not possible to explore the relation between infection level and relative yield loss at low levels of infection. The relatively narrow range of infection levels also made it hard to con- clude whether the maximum relative yield loss was attained at the highest infection level. This was particularly true for Tiémarifing and Framida, which did not yet reach $100 \%$ yield loss. Consequently, the exact course of the relation between Striga infection level and relative yield loss could not be completely resolved with the 2003 experiments.

In two of the three experiments, the narrow range of infection levels for each genotype, combined with the distinct differences in resistance level among genotypes, resulted in the absence of a common infection range for all genotypes. Hence, a direct comparison of tolerance between the various genotypes was not possible. However, some indications for differences in tolerance between genotypes were obtained. In 2003S, Framida and Tiémarifing had comparable relative yield losses; however, the average Striga infection level of Tiémarifing was twice as high. This result suggests that Tiémarifing is the more tolerant genotype, confirming earlier conclusions from van Ast et al. (2000).

In an attempt to overcome the aforementioned problems, the Striga infestation range in the 2004 experiment was expanded. Each genotype was exposed to infestation levels that differed 128 -fold and the infestation range was made genotype specific. The more susceptible genotypes (CK60-B and E36-1) infestation levels varied from 0.0625 to 8 seeds $\mathrm{cm}^{-3}$, whereas the more resistant genotypes (Framida and Tiémarifing) were exposed to infestation levels varying between 0.125 and 16 seeds $\mathrm{cm}^{-3}$. The range of infection levels was much smaller than the range of infestation levels. The size of these infection ranges, expressed as the ratio between maximum and minimum infection level, varied between genotypes (CK60-B: 2.4; Tiémarifing: 2.8; E36-1: 4.4; Framida: 23.9). Again this demonstrates the density dependence of the relation between infestation and infection. Main reason for the narrow range of infection levels for three of the four genotypes was the absence of low infection levels ( $<10$ aboveground Striga plants). This indicates that, in order to obtain such low infection levels for susceptible genotypes, extremely low infestation levels are required, which comprises the risk of not obtaining any infection at all.

Despite the differences in Striga infection level among genotypes, a small overlapping range of infection levels was obtained. Under these conditions, Tiémarifing and Framida were significantly more tolerant than CK60-B and E36-1. Sensitivity of CK60-B was earlier reported by Gurney et al. (1995) while tolerance of Tiémarifing was observed by van Ast et al. (2000). However, to arrive at this conclusion, only $36 \%$ 
of the experimental units were used. This demonstrates that, regardless of practical difficulties, the strategy to create identical infection levels to facilitate a direct screening for tolerance is very inefficient.

Based on the outcomes of this study two modifications are made concerning the information on the defense mechanisms of different genotypes available at the onset of the study. First, Tiémarifing appeared not as susceptible as CK60-B and E36-1, though clearly less resistant than Framida. Second, Framida proved more tolerant than CK60-B and E36-1 though still less tolerant than Tiémarifing.

Main objective of the current study was not to compare genotypes at identical infection levels, but rather to resolve the relation between Striga infection level and yield loss of the host. It was anticipated that clarification of this relation would enable the development of a suitable screening procedure for tolerance. In Figure 4, a three-quadrant representation of the relationship between infestation level, infection level and relative yield loss is given for the results obtained in $2004 \mathrm{~W}$. This presentation form was adopted from the nutrient supply, nutrient uptake and crop yield response curves introduced by de Wit (1953). The figure is composed of three

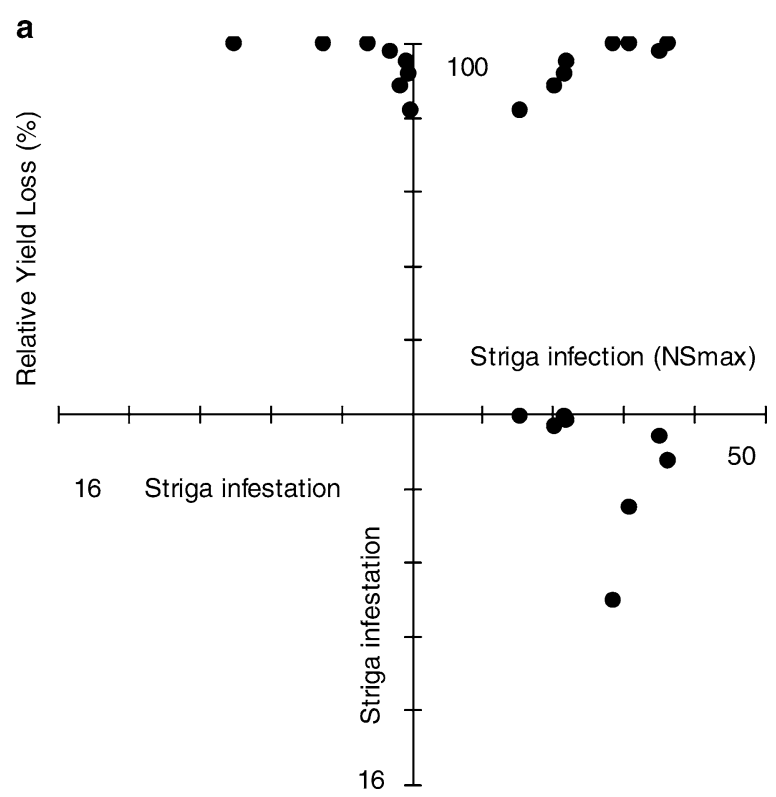

(a)

Figure 4. Three-quadrant representations of the relations between Striga infestation level, Striga infection level $\left(\mathrm{NS}_{\max }\right)$ and relative yield loss (\%) of four different sorghum genotypes: CK60-B (a), E36-1 (b), Framida (c) and Tiémarifing (d), as observed in 2004 in the greenhouse in Wageningen $(2004 \mathrm{~W})$.

(Continued)

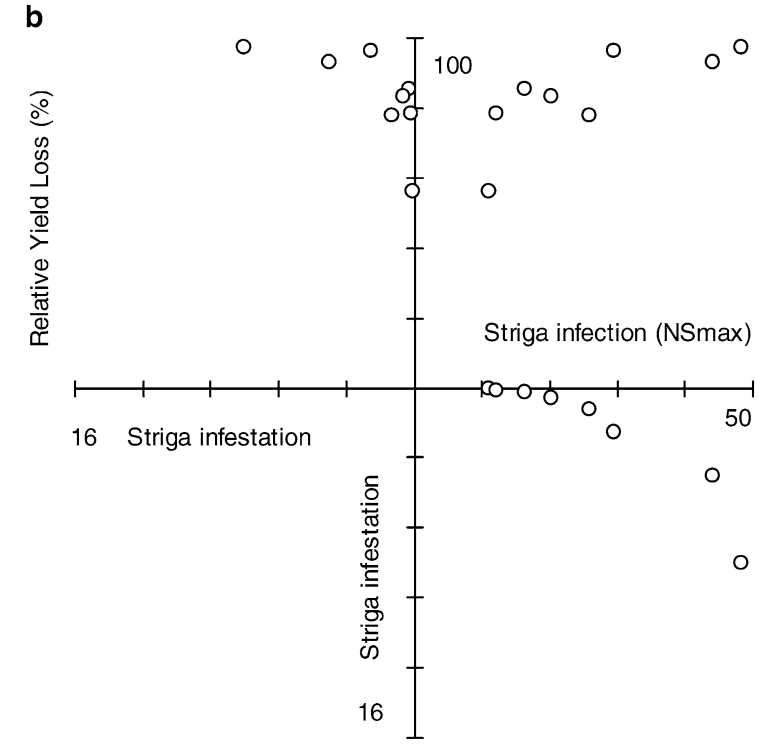

C

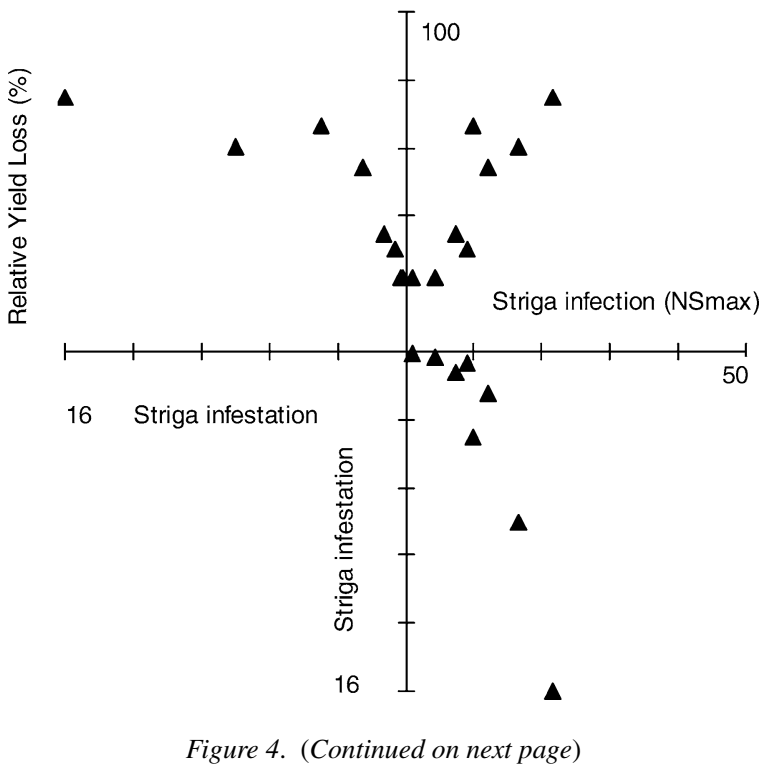

quadrants, where the upper-left quadrant (quadrant II) represents the relation between Striga infestation level and relative yield loss, the lower-right quadrant (quadrant IV) represents the relation between Striga infestation level and Striga infection level and the upper-right quadrant (quadrant I) represents the relation between Striga infection level and relative yield loss. Note that in this figure, in contrast to Figures 1 and 2, Striga infestation level is presented on a linear scale. Quadrant 


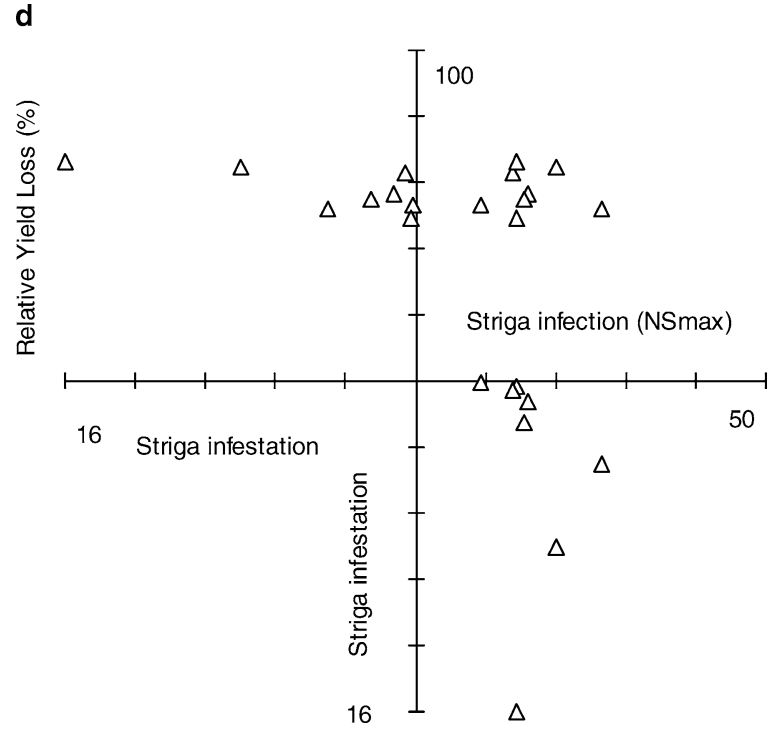

Figure 4. (Continued)

II shows two main response types to Striga infestation. CK60-B and E36-1 (Figure 4a and 4b, respectively) represent genotypes where complete or nearly complete yield losses were attained at low infestation levels. Framida and Tiémarifing (Figure $4 \mathrm{c}$ and $4 \mathrm{~d}$, respectively) represent genotypes where relative yield losses seem to stabilise around $60-70 \%$ at high infestation levels. The main difference between these two genotypes was that Tiémarifing obtained this level already at low infestation levels, whereas with Framida a more gradual increase in relative yield loss with infestation level was observed. For Orobanche (spp.) in carrot and pea, Bernhard et al. (1998) found a rectangular hyperbola describing the relation between seed infestation level and yield loss. At low infestation levels they observed a gradual increase in yield loss with increasing infestation level, comparable to what was observed with Framida, resulting in complete crop failure at high infestation levels, identical to the results obtained with CK60-B and E36-1.

The two quadrants on the right hand side provide further information on how the relation between Striga infestation level and relative yield loss was achieved. Quadrant IV contains the relation between Striga infestation and Striga infection and as such shows the level of resistance of a certain genotype. For both E36-1 and Framida this relation developed according to a rectangular hyperbola. Such a relationship between Striga infestation and Striga infection level was previously reported by Smith and Webb (1996) and confirms the earlier observation on density dependence. With E36-1, low infestation levels resulted in relatively high infection levels and the number of infections further increased in response to higher Striga seed densities. Framida was more resistant, with few infections at low infestation levels and the number of infections increased slowly as infestation level increased. Another type of response was observed with CK60-B and Tiémarifing. For those two genotypes, relatively high infection rates were observed at low seed densities: however, the infection rate did not continue to rise as infestation levels increased. CK60-B differed from Tiémarifing as it had a steeper initial increase in number of infections, it attained its maximum infection level at a lower infestation level, and its maximum number of infections was higher. The relationships observed for CK60-B and Tiémarifing could result from a reduced carrying capacity of the host plant at higher infestation levels, following reduced host vigour. It could also result from increased intra-specific competition following a higher number of belowground Striga attachments or from a combination of both. Consequently, screening for host plant resistance under very high infestation levels, using number of aboveground Striga plants as screening measure, might result in underestimation of susceptibility. Kim et al. (1998) and Haussmann et al. (2000) also suggested that this might be possible.

Quadrant I represents the relationship between Striga infection and relative yield loss and conveys the level of tolerance of a certain genotype. Three genotypes (CK60-B, E36-1 and Tiémarifing) seemed to reach or approach their maximum relative yield losses in 2004. Complete crop failure was observed for CK60$\mathrm{B}$ and E36-1, whereas the maximum relative yield loss for Tiémarifing was only around $57 \%$. For these three genotypes, the relative yield loss at low infection levels was not observed and remained unresolved. For Framida, the relationship between infection and relative yield loss was observed over a wide range and in this trajectory a nearly linear increase in relative yield loss was observed with an average yield loss of $4 \%$ per Striga infection. Koskela et al. (2002) reported a similar relationship between parasite infection level and host damage for the holoparasite Cuscuta europaea parasitizing on Urtica dioica. Gurney et al. (1999) found a negative and exponential relationship between yield and parasite load for Striga hermonthica parasitizing on sorghum, where parasite load was expressed as Striga dry weight. These findings do not necessarily 
contradict findings of the current study. Rather, given the difficulties of obtaining a complete infection range for a single genotype, the current observations only cover parts of the relation between infection level and relative yield loss. Also with Framida one might expect that the relation between infection level and relative yield loss will eventually reach a saturation level. Whether this saturation level corresponds to complete crop failure or is found at a lower level of yield reduction remains unresolved. It is evident that the saturation level of the relation between infection level and relative yield loss is one of the ways through which tolerance could come to expression. Tiémarifing is an example of this. At the same time, the three genotypes for which a maximum relative yield loss was observed will possess an initial trajectory in which the relative yield loss increases with infection level. E36-1 already shows part of this trajectory. The steepness of this initial increase, expressed as relative yield loss per Striga plant, represents another expression of tolerance. However, the lack of data points in these initial parts of the curve for CK60-B, E36-1 and Tiémarifing did not allow a comparison with Framida for this expression. For the same reason it remains unclear whether a lower maximum relative yield loss, as observed for Tiémarifing, goes along with a reduced initial slope, or whether those two exist independently.

Conducting large scale screening for tolerance at multiple infestation levels is not realistic as, due to other requirements, the number of screening plots will easily become too large. Determination of the relative yield loss already requires the presence of Striga-free control plots adjacent to Striga infested plots (e.g. Gurney et al., 1999; Rodenburg et al., 2005). Control plots in the field can be created by use of methyl bromide (e.g. Gurney et al., 1999) or ethylene injections (e.g. Bebawi et al., 1985; Bebawi \& Eplee, 1986) which are both rather expensive and laborious. An alternative is the infestation of Striga free fields, which is undesirable. Furthermore, measures should be taken to prevent contamination of control plots with Striga seeds from adjacent infested plots. Additionally, for a reliable selection, also sufficient replications $(\geq 5)$ are needed as was already shown by Haussmann et al. (2000). Finally, due to variation in Striga virulence (e.g. Bebawi et al., 1981), and significant genotype $\times$ environment interactions (e.g. Haussmann et al., 2001a; Oswald \& Ransom, 2004), stability of tolerance levels in a genotype should be tested at multiple locations.

Kim (1991) suggested that screening for tolerance could best take place at high infestation levels. The current results indicate that differences in maximum relative yield loss, and thus tolerance, between susceptible and moderately resistant genotypes can well be detected in this way, as was shown by the comparison between Tiémarifing, CK60-B and E36-1. For more resistant genotypes this approach proved less suitable, due to the fact that it was not possible to obtain infection levels that are high enough to cause the maximum relative yield loss. For breeding programs that try to develop genotypes that combine superior resistance with high levels of tolerance, as suggested by Ramaiah and Parker (1982), Haussmann et al. (2000) and Pierce et al. (2003), screening based on the maximum relative yield loss seems less appropriate, as particularly the expression of tolerance at lower infection levels is of interest. For those resistant genotypes, expressing tolerance as the ratio between relative yield loss and infection level seems more appropriate. Main bottleneck here is that if the relation between relative yield loss and infection level is described by a rectangular hyperbola, this ratio will decrease with increasing infection level. Such a linkage with resistance hampers an unbiased estimation of tolerance. Screening at more than one infestation level might improve the estimation of the proposed ratio, but, as was mentioned earlier, is not a realistic option.

In conclusion, two compatible tolerance measures are proposed based on yield response. For resistant genotypes a reduced relative yield loss per aboveground Striga plant indicates tolerance, whereas for less resistant genotypes the relative yield loss as such provides the best indication. Consequently, screening for tolerance based on the yield response of a genotype is difficult when the selection pool contains genotypes with largely different and unknown levels of resistance. As the need for unravelling resistance and tolerance is evident, the results of this study emphasize the need for a proper alternative method for screening for tolerance.

\section{Acknowledgments}

Financial assistance for this study was made possible through the beneficence of the Netherlands Foundation for the Advancement of Tropical Research (WOTRO). We acknowledge contributions, support and availability of facilities of Wageningen University (WUR), Wageningen Plants Sciences Experimental Center (WPSEC), the International Crop Research Institute for the Semi-Arid Tropics (ICRISAT) and the 
Africa Rice Center (WARDA). We especially thank Jacques Withagen, Ans Hofman, Henriette Drenth and Justin Lado Mairi of WUR, Geurt Versteeg, Peter Saat, Taede Stoker and Henk Meurs of WPSEC and Ana Amosse Dolo, Eva Weltzien, Ibrahima Sissoko and Badara Diallo of ICRISAT-Mali. Mitch Tuinstra from Kansas State University is kindly acknowledged for his comments on an earlier version of the manuscript.

\section{References}

Adetimirin, V.O., S.K. Kim \& M.E. Aken'Ova, 2000a. Expression of mature plant resistance to Striga hermonthica in maize. Euphytica 115: $149-158$.

Adetimirin, V.O., S.K. Kim \& M.E. Aken' Ova, 2000b. An alternative method of screening maize for tolerance to Striga. Afr Crop Sci J 8: 171-178.

Arnaud, M.C., C. Veronesi \& P. Thalouarn, 1999. Physiology and histology of resistance to Striga hermonthica in Sorghum bicolor var. Framida. Aust J Plant Physiol 26: 63-70.

van Ast, A., L. Bastiaans \& M.J. Kropff, 2000. A comparative study on Striga hermonthica interaction with a sensitive and a tolerant sorghum cultivar. Weed Res 40: 479-493.

Bebawi, F.F., 1981. Intraspecific physiological variants of Striga hermonthica. Exp Agr 17: 419-423.

Bebawi, F.F., R.E. Eplee \& R.S. Norris, 1985. The dispersion of backpack-applied ethylene in soil. Weed Sci 33: 74-77.

Bebawi, F.F. \& R.E. Eplee, 1986. Efficacy of ethylene as a germination stimulant of Striga hermonthica seed. Weed Sci 34: 694698.

Bernhard, R.H., J.E. Jensen \& C. Andreasen, 1998. Prediction of yield loss caused by Orobanche spp. in carrot and pea crops based on soil seedbank. Weed Res 38: 191-197.

DeVries, J., 2000. The inheritance of Striga reactions in maize. In: B.I.G. Haussmann, D.E. Hess, M.L. Koyama, L. Grivet, H.F. W. Rattunde \& H.H. Geiger (Eds.). Breeding for Striga resistance in cereals: proceedings of a workshop held at IITA, Ibadan, pp. 7384. Margraf Verlag, Weikersheim.

Efron, Y., 1993. Screening maize for tolerance to Striga hermonthica. Plant Breeding 110: 192-200.

El Hiweris, S.O., 1987. Nature of resistance to Striga hermonthica (Del.) Benth. parasitism in some Sorghum vulgare (Pers.) cultivars. Weed Res 27: 305-312.

Gurney, A.L., M.C. Press \& J.K. Ransom, 1995. The parasitic angiosperm Striga hermonthica can reduce photosynthesis of its sorghum and maize hosts in the field. J Exp Bot 46: 18171823.

Gurney, A.L., M.C. Press \& J.D. Scholes, 1999. Infection time and density influence the response of sorghum to the parasitic angiosperm Striga hermonthica. New Phytol 143: 573-580.

Gurney, A.L., M. Adcock, J.D. Scholes \& M.C. Press, 2000. Physiological processes during Striga infestation in maize and sorghum. In: B.I.G. Haussmann, D.E. Hess, M.L. Koyama, L. Grivet, H.F.W. Rattunde \& H.H. Geiger (Eds.). Breeding for Striga resistance in cereals: proceedings of a workshop held at IITA, Ibadan, Nigeria, pp. 3-18. Margraf Verlag, Weikersheim.
Gurney, A.L., A. Taylor, A. Mbwaga, J.D. Scholes \& M.C. Press, 2002. Do maize cultivars demonstrate tolerance to the parasitic weed Striga asiatica? Weed Res 42: 299-306.

Haussmann, B.I.G., D.E. Hess, H.G. Welz \& H.H. Geiger, 2000. Improved methodologies for breeding Striga-resistant sorghums. Field Crop Res 66: 195-211.

Haussmann, B.I.G., D.E. Hess, B.V.S. Reddy, S.Z. Mukuru, M. Kayentao, H.G. Welz \& H.H. Geiger, 2001a. Pattern analysis of genotype $\times$ environment interaction for Striga resistance and grain yield in African sorghum trials. Euphytica 122: 297-308.

Haussmann, B.I.G., D.E. Hess, B.V.S. Reddy, S.Z. Mukuru, M. Kayentao, H.G. Welz \& H.H. Geiger, 2001b. Quantitative-genetic parameters of sorghum growth under Striga infestation in Mali and Kenya. Plant Breeding 120: 49-56.

Hess, D.E., 1989. Resistance to Striga hermonthica (Del.) Benth. in sorghum. PhD thesis, Purdue University, pp 240.

Kim, S.K., 1991. Breeding for tolerance and general resistance in Maize: A novel approach to combatting Striga in Africa. Improving Striga management in Africa: 2nd general workshop of the Pan-African Striga Network (PASCON), Nairobi, Kenya, pp. 168-176.

Kim, S.K., 1994. Genetics of maize tolerance of Striga hermonthica. Crop Sci 34: 900-907.

Kim, S.K., J.M. Fajemisin, C. The, A. Adepoju, J. Kling, B. Badu Apraku, M. Versteeg, R.J. Carsky \& S.T.O. Lagoke, 1998. Development of synthetic maize populations for resistance to Striga hermonthica. Plant Breeding 117: 203-209.

Kim, S.K., V.O. Adetimirin, C. The \& R. Dossou, 2002. Yield losses in maize due to Striga hermonthica in West and Central Africa. Int J Pest Manage 48: 211-217.

Kling, J.G., J.M. Fajemisin, B. Badu Apraku, A. Diallo, A. Menkir \& A. Melake Berhan, 2000. Striga resistance breeding. In: B.I.G. Haussmann, D.E. Hess, M.L. Koyama, L. Grivet, H.F.W. Rattunde \& H.H. Geiger (Eds.). Breeding for Striga resistance in cereals: proceedings of a workshop held at IITA, Ibadan, pp. 103-118. Margraf Verlag, Weikersheim.

Koskela, T., S. Puustinen, V. Salonen \& P. Mutikainen, 2002. Resistance and tolerance in a host plant-holoparasitic plant interaction: genetic variation and costs. Evolution 56: 899-908.

Obilana, A.T., 1983. Striga studies and control in Nigeria. 2nd International Workshop on Striga, Ouagadougou, Upper Volta, pp. 87-98. ICRISAT, Patancheru.

Omanya, G.O., B.I.G. Haussmann, D.E. Hess, B.V.S. Reddy, M. Kayentao, H.G. Welz \& H.H. Geiger, 2004. Utility of indirect and direct selection traits for improving Striga resistance in two sorghum recombinant inbred populations. Field Crop Res 89: 237-252.

Oswald, A. \& J.K. Ransom, 2004. Response of maize varieties to Striga infestation. Crop Prot 23: 89-94.

Parker, C. \& C.R. Riches, 1993. Parasitic weeds of the world: Biology and control. Cab International, Wallingford, Oxon

Pierce, S., A.M. Mbwaga, M.C. Press \& J.D. Scholes, 2003. Xenognosin production and tolerance to Striga asiatica infection of highyielding maize cultivars. Weed Res 43: 139-145.

Ramaiah, K.V. \& Parker, C., 1982. Striga and other weeds in sorghum. In: L.R. House, L.K. Mughogho, J.M. Peacock (Eds.). Sorghum in the eighties. Proceedings of the international symposium on sorghum. Vol 1. pp. 291-302.

Rodenburg, J., L. Bastiaans, E. Weltzien \& D.E. Hess, 2005. How can selection for Striga resistance and tolerance based on field observations be improved? Field Crop Res 93: 34-50. 
Showemimo, F.A., 2003. Selection Criteria for Combining High Yield and Striga Resistance in Sorghum. Tropicultura 21: 157159.

Smith, M.C. \& M. Webb, 1996. Estimation of the seedbank of Striga spp. (Scrophulariaceae) in Malian fields and the implications for a model of biocontrol of Striga hermonthica. Weed Res 36: 85-92.

Sokal, R.R. \& F.J. Rohlf, 1995. Biometry.W.H. Freeman and Company, New York.
Wilson, J.P., D.E. Hess \& W.W. Hanna, 2000. Resistance to Striga hermonthica in wild accessions of the primary gene pool of Pennisetum glaucum. Phytopathology 90: 1169-1172.

Wilson, J.P., D.E. Hess, W.W. Hanna, K.A. Kumar \& S.C. Gupta, 2004. Pennisetum glaucum subsp. monodii accessions with Striga resistance in West Africa. Crop Prot 23: 865-870.

Wit de, C.T., 1953. A physical theory on placement of fertilizer. PhD thesis. Landbouw Hogeschool Wageningen. pp. 71. 